\title{
Palliative Medicine
}

http://pmj.sagepub.com

\section{Difficulty of symptom control and general practitioners' knowledge of patients' symptoms \\ GE Grande, Sig Barclay and CJ Todd \\ Palliat Med 1997; 11; 399 \\ DOI: $10.1177 / 026921639701100511$}

The online version of this article can be found at:

http://pmj.sagepub.com/cgi/content/abstract/11/5/399

\author{
Published by: \\ @SAGE \\ http://www.sagepublications.com
}

Additional services and information for Palliative Medicine can be found at:

Email Alerts: http://pmj.sagepub.com/cgi/alerts

Subscriptions: http://pmj.sagepub.com/subscriptions

Reprints: http://www.sagepub.com/journalsReprints.nav

Permissions: http://www.sagepub.co.uk/journalsPermissions.nav

Citations http://pmj.sagepub.com/cgi/content/refs/11/5/399 


\section{Difficulty of symptom control and general practitioners' knowledge of patients' symptoms}

GE Grande Research officer, Cambridgeshire Family Health Services Authority, Cambridge, SIG Barclay General Practitioner, East Barnwell Health Centre, Cambridge and CJ Todd Senior Research Associate and Acting Director of Health Services Research Group (HSRG), Department of Community Medicine, University of Cambridge, Cambridge

Key words: communication; palliative care; primary health care; symptom control (non-MESH)

The purpose of this study was to investigate barriers to adequate symptom control in palliative care within primary care by surveying health professionals' perceptions of their ability to control symptoms and awareness of their patients' symptoms.

General practitioners (GPs) and district nurses were surveyed about general views of symptom control. Interviews with terminally ill patients were conducted, and GPs completed questionnaires about these specific patients.

GPS and district nurses differed greatly in the symptoms they felt confident in controlling. There was generally low agreement between patients' and GP's reports of patients' symptoms. GPs were most likely to miss symptoms which were perceived to be difficult to control and which were less prevalent in the patient sample.

As GPs and district nurses differ in the symptoms they feel confident in controlling, close teamwork between the two professions may enhance the prospects for adequate control of some symptoms. Perceived ability to control symptoms and the prevalence of symptoms may both influence which symptoms come to the attention of the GP. Unless GPs ask directly about symptoms, many symptoms are likely to be missed.

Mots clés: communication; soins palliatifs; premiers soins médicaux, contrôle des symptômes

Le but de cette étude était d'examiner les obstacles au contrôle adéquat des symptômes dans les soins palliatifs survenant lors des premiers soins en étudiant les perceptions des professionnels de la santé, leur capacité à contrôler les symptômes et la connaissance des symptômes de leurs patients.

Les médecins généralistes et les infirmières de district différaient beaucoup sur l'assurance qu'ils ont à contrôler les symptômes. En général il $y$ avait peu de concordance entre les rapports des patients et ceux des

Address for correspondence: Mrs Gunn Grande, Research Associate, Health Services Research Group, Department of Community Medicine, University of Cambridge, University Forvie Site, Robinson Way, Cambridge CB2 2SR, UK. 
médecins sur les symptômes des patients. Ce sont les symptômes considérés comme difficile à contrôler et moins fréquents dans l'échantillon du patient qui ont le plus échappé aux médecins généralistes.

Étant donné que les médecins généralistes et les infirmières de district diffèrent sur l'assurance qu'ils ont à contrôler les symptômes, un travail d'équipe rigoureux entre les deux professions peut améliorer les perspectives d'un contrôle adéquat de certains symptômes. Une aptitude constatée à contrôler les symptômes et la fréquence des symptômes peuvent influencer les symptômes qui retiendront l'attention du médecin généraliste. A moins que les médecins généralistes ne se renseignent immédiatement sur les symptômes, ces derniers risquent d'échapper aux médecins.

\section{Introduction}

Twenty years ago research identified considerable deficiencies in home-based symptom control for the terminally ill, ${ }^{1}$ the presence of severe pain often giving rise to acute hospital admission. ${ }^{2}$ Although there have been considerable advances in the pharmacology and technology of pain control since then, recent research still highlights problems in providing pain relief in the primary care setting. ${ }^{3,4}$ Furthermore there is considerable scope for improvement in the control of symptoms other than pain, ${ }^{3,5,6}$ and symptom control in general remains a major reason for admission to hospital or hospice. ${ }^{7}$

Some improvements in symptom control are likely to be gained through further training and clinical research. However, adequate symptom control also requires that symptoms are communicated to the appropriate health professional in the first place. Cartwright et al. ${ }^{1}$ found that patients consulted their family doctor or general practitioner (GP) about only two-thirds of their symptoms. For a quarter of symptoms, patients did not consult anybody. Symptoms for which patients failed to seek help included some which caused considerable distress and which had been present for a year or more. The symptoms about which patients were least likely to consult were those for which little relief was obtained even when a patient did consult somebody. ${ }^{1}$ One reason for not consulting may therefore be a realistic assessment of the probable outcome. Hence adequate control of certain symptoms may be impeded by the cumulative effect of lack of expertise in symptom control among professionals and lack of communication about symptoms by patients. In order to investigate this we interviewed terminally ill patients and conducted a survey of GPs and district nurses. District nurses in the UK provide nursing care in the patient's home and help organize other home support that is required.

\section{Subjects and methods}

We randomly selected 150 of the 354 GP principals in Cambridgeshire from the Family Health Services Authority register and asked them to identify all patients on their lists with a life expectancy of a year or less, for whom care had switched from curative to palliative, and who were being looked after at home. Eighty GPs nominated 105 patients, including patients of $13 \mathrm{GP}$ partners. Thirty patients were subsequently revealed to be too ill to deal with an interview or died prior to being contacted. Of the 75 patients contacted, 43 were interviewed, while 18 refused and 14 became too ill after initial contact. GPs were asked to complete a patient-specific questionnaire for patients approached for an interview. From these questionnaires GPs' reports of presence of patient symptoms were obtained for 30 of the patients interviewed. Patients were also asked about their mobility and contact with health professionals.

A general questionnaire on palliative care was sent to all the 150 GPs randomly selected for the study and to the 13 GP partners whose patients were nominated. Responses were received from 127 $(85 \%)$ of the random sample and from all of the 13 GP partners. The same questionnaire was also sent to all 101 district nurse sisters in the county; 73 of the nurses responded (72\%). 
The general questionnaire on palliative care asked GPs and district nurses to rate the difficulty of controlling a range of symptoms in terminally ill patients using five-point scales, ranging from 1: "Not at all difficult' to 5: 'Very difficult' (Table 1 lists the symptoms). The patient-specific questionnaire asked GPs to indicate which symptoms the patient experienced using the same list of symptoms. During the patient interview the researcher also read the list of symptoms to the patient (with the exception of 'bad smell') and asked him/her to indicate which symptoms he/she had experienced over the last month.

The Mann-Whitney test was used to test differences between GP and district nurse ratings of symptom control difficulty. Pearson's correlation coefficient was calculated to investigate relationships between ratings of symptom control difficulty, symptom prevalence and discrepancy in reports of symptoms. The statistical software used was SPSS for Windows $6.0 .^{8}$ All tests of significance were two-tailed.

\section{Results}

\section{Patient characteristics}

Cancer patients were over-represented in the study. Of the patients approached $93 \%$ had cancer while only $26 \%$ of deaths in the population are from cancer. ${ }^{9}$ The interview sample was also necessarily limited to patients who were sufficiently well to participate in an interview. They were therefore predominantly in the early stages of terminal illness, retained a degree of mobility and had limited nursing requirements. Median time to death from referral to the study was 182 days. Twenty-eight of

Table 1 List of symptoms used for the study

\begin{tabular}{l} 
- Pain \\
- Lleeplessness \\
- Noss of appetite \\
- Constipation \\
- Breathlessness \\
- Lack of bladder control \\
- Unpleasant smell \\
- Bedsores \\
- Anxiety \\
\hline
\end{tabular}

the 30 interviewed patients were able to move about indoors independently although 14 did so with difficulty. Nineteen reported being able to move about outdoors independently. Only 14 patients had regular contact with a district nurse, i.e. at least monthly. Nevertheless, the percentage of patients who reported having a symptom correlated highly with the percentage reported in a national sample of terminally ill patients for the 11 symptoms investigated $(r=0.8508, N=11, \mathrm{P}=0.001) .^{3}$

\section{GP and district nurse ratings of difficulty of symptom control}

As the base from which percentages are calculated may vary depending on the actual number of GPs and nurses who completed each question, both numbers and percentages are reported below. Figure 1 shows the percentage of GPs and district nurses who gave a rating of 'quite difficult' (4) or 'very difficult' (5) to control for each symptom. This allows us to focus on those instances when a symptom was perceived to be problematic.

The symptoms considered to be problematic by the largest number of GPs were loss of appetite ( 68 GPs, $49 \%)$, lack of bowel control $(58,43 \%)$ and unpleasant smell $(54,40 \%)$. Other symptoms rated as difficult by a large proportion were lack of bladder control $(47,35 \%)$, breathlessness (47, $35 \%)$, bedsores $(46,34 \%)$ and depression (43, $31 \%)$. Few felt that sleeplessness $(12,9 \%)$ and pain $(11,8 \%)$ were very or quite difficult to control.

In contrast, the symptoms considered to be problematic by the largest number of district nurses were loss of appetite $(37,54 \%)$, depression $(37,54 \%)$ and anxiety $(36,51 \%)$, followed by nausea/vomiting $(26$, $37 \%)$, constipation $(22,32 \%)$, breathlessness $(22$, $31 \%)$ and sleeplessness $(20,30 \%)$. Pain was considered very or quite difficult by 15 nurses $(26 \%)$. The symptoms least likely to be viewed as problematic by district nurses were lack of bowel control $(8,12 \%)$ and lack of bladder control $(6,9 \%)$.

Compared with GPs district nurses tended to give significantly higher ratings of difficulty for pain $(U=3687, \mathrm{P}=0.006)$, sleeplessness $(U=3277$, $\mathrm{P}=0.0004)$, anxiety $(U=3082, \mathrm{P}<0.0001)$ and depression $(U=3341, \mathrm{P}=0.0006)$. Conversely, district nurses tended to give lower ratings of difficulty than GPs for lack of bladder control $(U=2469$, $\mathrm{P}<0.0001)$, lack of bowel control $(U=2287, \mathrm{P}<$ $0.0001)$, unpleasant smell $(U=3611, \mathrm{P}=0.023)$ and 
bedsores $(U=2925, \mathrm{P}=0.0001)$. Thus district nurses appeared more confident than GPs about controlling lack of bowel and bladder control, unpleasant smell and bedsores. GPs on the other hand showed more confidence than nurses in relation to pain, sleeplessness, depression and anxiety. Some symptoms, however, appear to present problems to both groups. More than $30 \%$ of both GPs and district nurses reported breathlessness, loss of appetite and depression to be very or quite difficult to control.

\section{Comparison of the GPs' and patients' reports of presence of symptoms}

For simplicity, in presenting the results we presume that patients' report of symptoms represents 'the gold standard'. The 30 patients for whom we had comparable GP data, reported the presence of 149 symptoms in total, representing a mean of 4.97 symptoms each. The GPs reported the presence of 98 symptoms in the patient sample; a mean of 3.27 per patient. The overall tendency was for GPs to report fewer instances of each symptom than patients, with the one exception of loss of appetite. GPs reported 18 instances of this symptom in the patient sample while patients reported 17 (Table 2). Exploratory data analysis ${ }^{10}$ (Figure 2) suggested a relationship between instances of a symptom reported by GPs as a percentage of instances reported by patients (Table 2 ) and the percentage of GPs who rated a symptom as difficult (Figure 1). However, loss of appetite appeared to represent a special case, and subsequent analysis therefore considered results both with and without appetite included. This is made clear by Figure 2 as $r=$ $-0.2242(N=11, \mathrm{P}=0.507)$ with loss of appetite included and $r=-0.8067(N=10, \mathrm{P}=0.005)$ with loss of appetite excluded.

As past research indicates that patients are more likely to consult doctors about symptoms for which they expect effective help, ${ }^{1}$ GPs may be less likely to be told about, and thus be aware of, the symptoms they are least able to control. The majority of discrepancies between patient and GP reporting did consist of the GP failing to report presence of symptom when the patient stated it was present. The higher the proportion of GPs rating a symptom as difficult, the higher the percentage of actual symptoms which GPs failed to report $(r=0.2835, n=11$ symptoms, $\mathrm{P}=0.398$ with appetite included, $r=$ $0.6694, N=10, \mathrm{P}=0.034$ with appetite excluded). However, in a few instances the GP reported that a symptom was present when the patient reported it as absent. The lower the proportion of GPs rating a symptom as difficult, the higher the number of instances for which the GP reported presence of a symptom when the patient did not $(r=-0.0526$, $N=11, \mathrm{P}=0.878$ with appetite included and $r=$ $-0.6237, N=10, \mathrm{P}=0.054$ with appetite excluded). Thus there are two trends combining to produce the pattern observed in Figure 2. First, the clearest tendency was for GPs to fail to report the symptoms which GPs generally perceived to be difficult to control. Secondly, there was a weaker tendency for GPs to over-report symptoms perceived to be easy to control. However, the latter relationship was nonsignificant and should be considered with caution. As 16 patients in our sample did not have regular contact with a district nurse, we were not able to assess the relationship between district nurse and patient report of symptoms.

Table 2 Number of patients who reported symptom, number of patients who had symptom according to their GP, and symptoms reported by GPs as a percentage of symptoms reported by patients

\begin{tabular}{lccc}
\hline & $\begin{array}{l}\text { Number of patients } \\
\text { reporting symptom } \\
(N)\end{array}$ & $\begin{array}{l}\text { Number of patients with } \\
\text { symptom according to GPs } \\
(N)\end{array}$ & $\begin{array}{l}\text { Symptoms reported by GPs as a } \\
\text { percentage of symptoms reported } \\
\text { by patients (\%) }\end{array}$ \\
\hline Lack of bowel control & 4 & 1 & 25 \\
Bedsores & 7 & 2 & 29 \\
Being depressed & 19 & 7 & $\mathbf{3 7}$ \\
Lack of bladder control & 7 & 3 & $\mathbf{4 3}$ \\
Trouble with breathing & 9 & 5 & $\mathbf{5 6}$ \\
Nausea/vomiting & 15 & 8 & $\mathbf{5 3}$ \\
Constipation & 21 & 14 & $\mathbf{6 7}$ \\
Sleeplessness & 13 & 9 & $\mathbf{6 9}$ \\
Pain & 24 & 20 & $\mathbf{8 3}$ \\
Feeling anxious & 13 & 11 & $\mathbf{8 5}$ \\
Loss of appetite & 17 & 18 & 106 \\
\hline
\end{tabular}




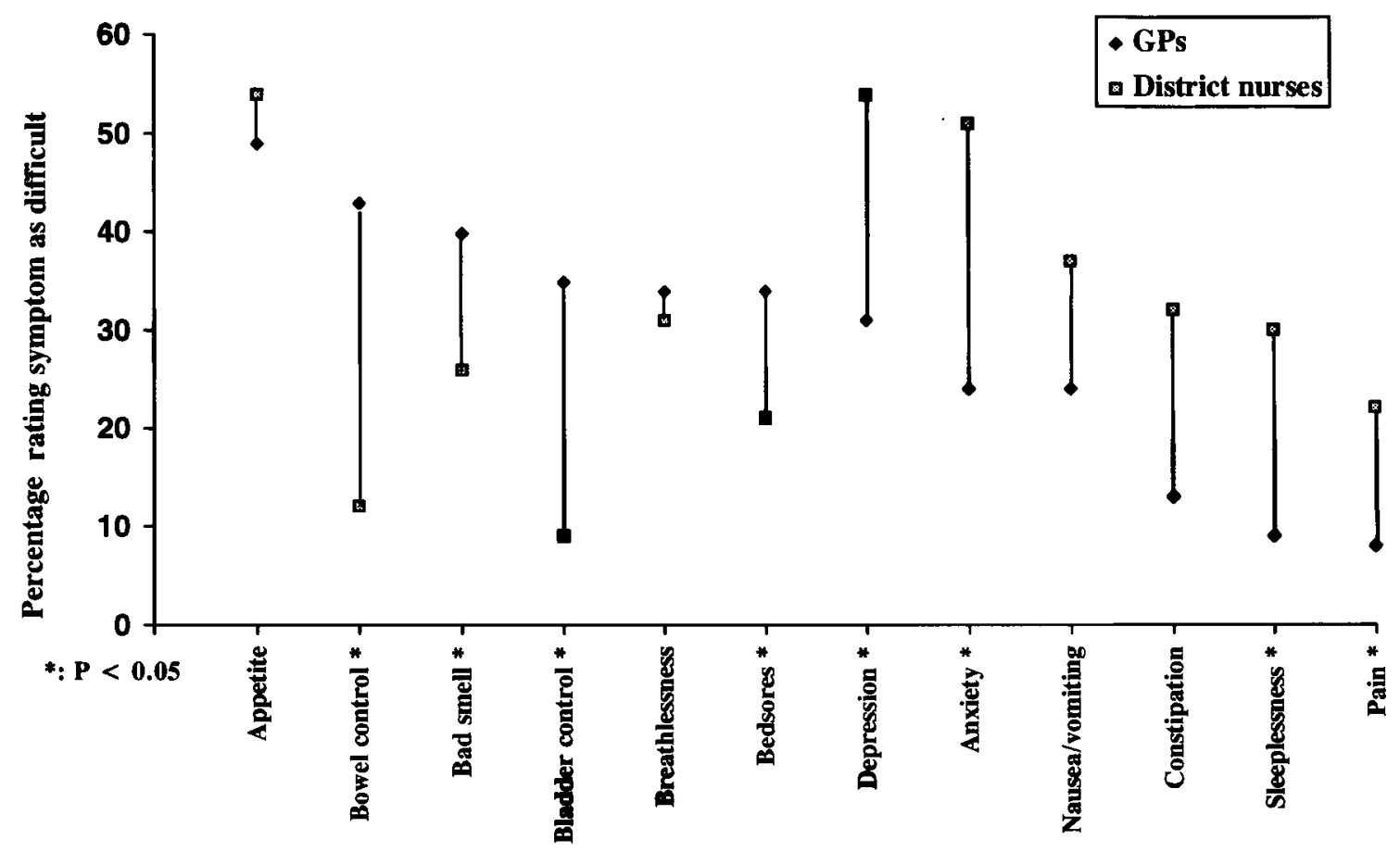

Figure 1 Percentage of GPs and district nurses who rated a symptom as very or quite difficult

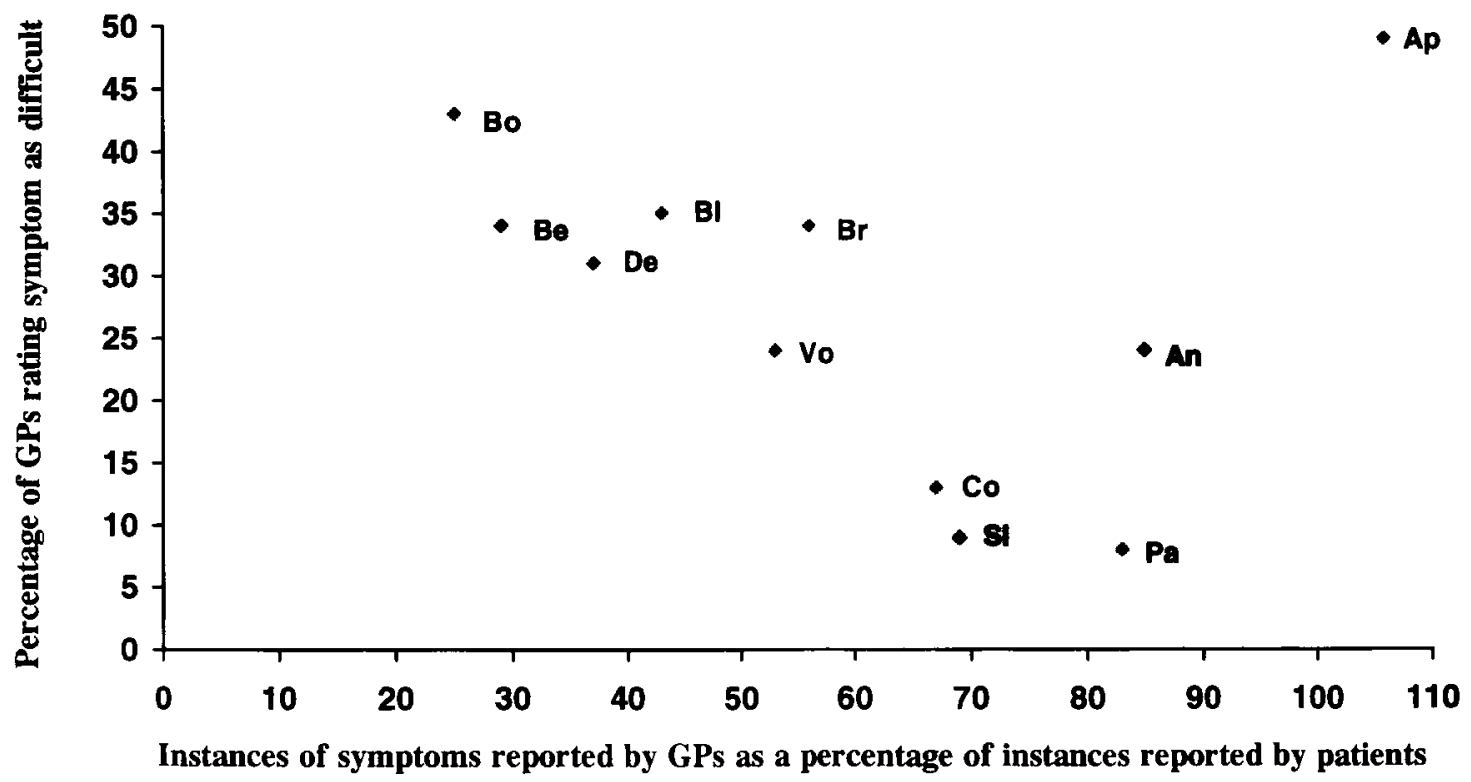

Figure 2 Percentage of GPs rating a symptom as very or fairly difficult versus percentage of patients' symptoms reported by GPs. An: anxiety, Ap: loss of appetite, Be: bedsores, Bl: bladder control, Bo: bowel control, Br: breathlessness, Co: constipation, De: depression, Pa: pain, SI: sleeplessness, Vo: nausea/vomiting. 
Symptom prevalence was found to correlate both with perceived difficulty of symptom control and awareness of a patient's symptoms and may explain the observed pattern. We found that the higher the percentage of patients who had a symptom, the lower the percentage of GPs rating the symptom as difficult $(r=-0.5354, N=11, \mathrm{P}=0.090$ with appetite included, $r=-0.7851, N=10, \mathrm{P}=0.007$ with appetite excluded). Iikewise, the higher the percentage of patients who had a symptom, the lower the percentage of instances of the symptom missed by the GP ( $r=-0.6719, n=11, \mathrm{P}=0.024$ with appetite included, $r=-0.6559, N=10, \mathrm{P}=0.039$ with appetite excluded). However, prevalence was not related to GPs' over-reporting of symptoms. Furthermore, there was no similar relationship between prevalence and perceived difficulty of symptom control for the district nurses.

\section{Discussion}

The central findings in this paper are that GPs and district nurses differ greatly in their ratings of difficulty of symptom control, that GP and patient accounts of the patient's symptoms differ and that GPs may often be unaware of the symptoms they find most difficult to control.

\section{GP and district nurse rating of symptom control difficulty}

GPs and district nurses differ significantly in their ratings of symptom control difficulty for most symptoms. The differences appear to reflect the different roles of the two health professions. District nurses appear more confident about symptoms which require nursing care such as lack of bowel and bladder control, bedsores and unpleasant smell. GPs appear more confident about symptoms for which drugs can be administered, such as pain, sleeplessness, constipation and nausea/vomiting. Thus the ratings suggest that GPs and district nurses bring different strengths to palliative care in line with their traditional roles, and that prospects for adequate control of many symptoms may be improved by ensuring the combined involvement of both professions in a patient's care. However, research suggests that district nurses become involved too late in the care of the terminally ill. ${ }^{4}$ It could be argued that GPs should evaluate the symptom control needs of patients and call on district nurse help as and when necessary. However, if GPs are unaware of many symptoms, ${ }^{1}$ it may be difficult for them to assess all the symptom control needs of their patients. They may in particular fail to detect the onset of the symptoms which the district nurses feel most able to control, e.g. lack of bowel and bladder control.

We should note that some symptoms such as loss of appetite, breathlessness and depression were rated as difficult by a large proportion of both GPs and district nurses. Thus certain symptoms are less likely to be improved through increased teamwork and may in particular require further clinical research and professional training.

Confidence in ability to control a symptom does not guarantee adequate relief. While only $8 \%$ of GPs rated pain control as difficult, recent research suggests that there is poor pain control in the home. ${ }^{3}$ Although poor prescribing practice is a key cause,${ }^{4}$ inadequate pain control can also stem from professionals' difficulty in ascertaining the level of pain present. ${ }^{4,11}$ Thus even when there is the skill to control a symptom, adequate relief is dependent on clear communication. The situation is of course exacerbated when professionals both lack confidence in controlling a symptom and often do not know about its presence, let alone its severity.

\section{Comparison of patient and GP reports of symptoms}

The results reveal discrepancies between GPs' and patients' reports of patients' symptoms. Some of these may be due to study design. First, there was a short delay between receiving the clinical data from the GP and interviewing patients. Secondly, the GPs completed a brief questionnaire while the patients underwent an interview, and the former method may have tended to yield less complete data than the latter. GPs may also use stricter criteria for deciding presence or absence of some symptoms compared with patients. The latter is particularly attractive as an explanation for psychological symptoms, given the scope for differing interpretations. However, none of the above explains the systematic relationship found between symptom report discrepancy and ratings of symptom control difficulty.

A likely explanation for the observed patterns is that perceived difficulty of symptom control affects communication about symptoms. Cartwright et al.'s 1 
research suggests that patients fail to consult about symptoms for which they are unlikely to receive effective help. Hence GPs may tend not to know about the symptoms they feel least confident in controlling because patients, being aware of the general limits of GP skill or role, often fail to tell them about such symptoms. Furthermore, GPs themselves may feel more reluctant to ask about symptoms they feel less confident of controlling. One may also be more likely actively to seek evidence of symptoms one feels confident in controlling and therefore sometimes assume there is the presence of a symptom without a confirming patient report.

An alternative hypothesis is that the observed relationship between perceived difficulty and awareness of symptoms is due to the effect of symptom prevalence. The greater the prevalence of a symptom, the more GPs come into contact with it and the more confident they may feel in controlling it. Likewise, the greater the prevalence of a symptom, the more likely GPs may be to expect its presence and to look for it. However, while data support such an explanation for the GP sample, there was no evidence of a relationship between symptom prevalence and confidence in symptom control among the district nurses. We would need to show that district nurses are exposed to a patient population for whom symptom prevalence is distributed differently in order to support this hypothesis.

Loss of appetite was the exception to the overall pattern for all correlations involving GPs' perceived difficulty of symptom control, and it was the one symptom for which GPs reported more instances than patients. Loss of appetite may be seen as an inevitable part of advancing disease and thus be assumed to be present independently of patients' communication about the symptom. While other symptoms are more directly associated with suffering, and thus require more immediate attempts at relief, loss of appetite is not necessarily perceived as a symptom requiring treatment. The impetus to act may only arise if there is distress amongst patient or carer over weakness or weight loss. Thus the commonness of the symptom is not directly associated with greater practice in its control. The options available to the health professional are also limited where loss of appetite is concerned.

GPs and district nurses appear to possess different symptom control skills, and symptom control is likely to benefit from the involvement of both professional groups. Furthermore, this study and past research ${ }^{1}$ suggest that health professionals are less likely to know about the symptoms they feel least confident in controlling. Patients may be less likely to seek help about symptoms for which little relief will be obtained because they are aware of the limitations of a health professional's role. Health professionals may also be less likely to ask about symptoms with which they feel uncomfortable. The lack of awareness of symptoms highlights a general need to actively ask about symptoms rather than wait for the patient to take the initiative. Also, if patients are more likely to communicate certain symptoms to district nurses which relate to the nurses' perceived skill and role, this would further emphasize the need for early district nurse involvement in terminal illness.

\section{Acknowledgements}

We thank the GPs, district nurses and patients for their participation. We also thank our steering group members, Sandra Betterton, Elizabeth Challis, Jan Date, Janet Doyle, Catherine Johaheer and Glenys Pennock, for their advice and support, and Melanie Johnson for help in initiating the project. The study was a Cambridgeshire Family Health Services Authority project and was funded by the Department of Health and East Anglian Regional Health Authority. It was approved by the Cambridge, Huntingdon and Peterborough Local Research Ethics Committees.

\section{References}

1 Cartwright A, Hockey L, Anderson JL. Life before death. London: Routledge \& Kegan Paul, 1973.

2 Parkes CM. Home or hospital? Terminal care as seen by surviving spouses. J Roy Coll Gen Pract 1978; 28: 19-30.

3 Addington-Hall J, McCarthy M. Dying from cancer: results of a national population-based investigation. Palliat Med 1995; 9: 295-305.

4 Seale C, Cartwright A. The year before death. Aldershot: Avebury, 1994.

5 Jones RVH, Hansford J, Fiske J. Death from cancer at home: The carers' perspective. $\mathrm{Br}$ Med J 1993; 306: $249-51$.

6 Higginson I, McCarthy M. Measuring symptoms in terminal cancer: Are pain and dyspnoea controlled? J Roy Soc Med 1989; 82: 264-67. 
7 Herd EB. Terminal care in a semi-rural area. $B r J$ Gen Pract 1990; 40: 248-51.

8 Norusis MJ. SPSS for Windows Base System user's guide. Release 6.0. Chicago, IL: SPSS Inc, 1993.

9 OPCS. Mortality Statistics. Review of the Registrar General on deaths by cause, sex and age, in England and Wales, 1992. Series DH2, no. 19. London, HSMO, 1993.
10 Tukey, JW. Exploratory data analysis. Reading, MA: Addison-Wesley, 1977.

11 Larue F, Colleau SM, Brasseur L, Cleeland CS. Multicentre study of cancer pain and its treatment in France. Br Med J 1995; 310: 1034-37. 